\title{
Organization of Adult Motor Cortex Representation Patterns Following Neonatal Forelimb Nerve Injury in Rats
}

\author{
John P. Donoghue ${ }^{1}$ and Jerome N. Sanes ${ }^{2}$ \\ ${ }^{1}$ Center for Neural Science, Brown University, Providence, Rhode Island 02912, and "Human Motor Control Section, \\ Medical Neurology Branch, National Institute of Neurological and Communicative Disorders and Stroke, National Institutes \\ of Health, Bethesda, Maryland 20892
}

Somatotopic representation patterns in the motor cortex (MI) of rats that had a unilateral forelimb amputation on the first postnatal day were examined after 2-4 months of survival. Intracortical electrical stimulation and recording techniques were used to map the somatic representation in $\mathrm{MI}$ and in the somatic sensory cortex (SI). In normal rats, vibrissa, forelimb, and hindlimb areas comprise the bulk of the MI representation. Stimulation within the forelimb area elicits elbow, wrist, or digit movements at the lowest current intensities. The proximal limb representation appears to be contained within the distal forelimb area, since shoulder movements are nearly always evoked by stimulating at higher current intensities at some distal forelimb sites. In agreement with previous studies, the distal forelimb representation overlapped the adjacent part of the granular SI cortex. Following removal of the forelimb at birth, 3 novel features of MI organization were observed. First, the areas from which stimulation evoked movements of the vibrissa or the shoulder musculature were larger than normal. Stimulation thresholds were lower than those required for comparable movements in normal rats throughout these areas, suggesting that nerve section had not simply unmasked a high-threshold representation. Second, vibrissa movements were more commonly paired with movements of the proximal forelimb muscles at the same site. Third, stimulation in the adjacent granular SI cortex failed to evoke shoulder or trunk movements, although receptive-field mapping in this region showed that cells were responsive to cutaneous stimulation of the trunk and shoulder region. These results indicate that several organizational features develop differently in MI following perinatal nerve injury: certain remaining muscle groups have enlarged cortical representations, there is a strengthening of some normally weak connections from MI to the proximal musculature, and muscles are grouped in unusual combinations. These data demonstrate that the formation of MI representation patterns is strongly influenced by nerve injury during the perinatal period.

\footnotetext{
Received July 7, 1987; revised Dec. 30, 1987; accepted Dec. 31, 1987.

We thank M. McGavic, S. Ryan, B. L. Schlaggar, and S. Suner for their assistance in the data collection and anatomical analyses, J. Connell for preparation of the histological material and illustration construction, and $M$. Flinn-Butera for secretarial assistance. This work was supported by NIH Grant 1 R01 NS22517-01, March of Dimes Basil O'Connor Starter Scholar Award 5-562, and in part by the U.S. Office of Naval Research Contract N00014-81-K-0136.

Correspondence should be addressed to Dr. John P. Donoghue, Center for Neural Science, Brown University, Box 1953, Providence, RI 02912, or Dr. Jerome N. Sanes, NINCDS, Building 10, Room 5N-226, Bethesda, MD 20892.

Copyright (C) 1988 Society for Neuroscience $0270-6474 / 88 / 093221-12 \$ 02.00 / 0$
}

Developing mammals acquire a vast array of motor skills. These skills may be preserved intact throughout life, but they are commonly modified by subsequent motor learning. Immature mammals also exhibit extensive behavioral adaptation following central nervous system damage that disrupts the normal assembly or execution of motor programs (Kennard, 1942; Whishaw et al., 1986; but see Passingham et al., 1983). Although the motor cortex (MI) is believed to be an important component of skill learning, motor performance, and postinjury recovery in developing mammals, its roles in these functions is largely unknown.

It is now established that cerebral cortical representations of sensory structures are modifiable in early stages of development. For example, injury to somatic sensory or visual receptors or even selective forms of experience in young mammals enlarge cortical representations of intact receptor surfaces. Monocular enucleation or lid suture will shift the ocular dominance of visual cortical neurons from the deprived eye to the intact one (Hubel and Wiesel, 1965; see review by Sherman and Spear, 1982). In the somatic sensory system, destruction of sensory receptors or sectioning of peripheral nerves early in development is accompanied by an expanded somatic sensory cortex (SI) representation of unaffected nearby sensory surfaces (Waite and Taylor, 1978; Kalaska and Pomeranz, 1979; Pidoux et al., 1979; Kelehan ct al., 1981; Simons et al., 1984; Waite, 1984; Wall and Cusick, 1986). Changes in the visual cortex and SI appear to be most noticeable when experimental manipulations are carried out during an early "critical" period, but in some cases it has been shown that an ability for reorganization persists into adulthood or may even be greater than in neonates (see Wall and Cusick, 1986, for discussion and relevant references). Modifications in cortical representation patterns following neonatal manipulations may be accompanied by an altered structural and connectional organization in cortex (Van der Loos and Woolsey, 1973; Ryugo et al., 1975; Weller and Johnson, 1975; Killackey et al., 1976; Woolsey and Wann, 1976; Hubel et al., 1977; Steffen and Van der Loos, 1980; Harris and Woolsey, 1981; Jeanmonod et al., 1981). Despite our knowledge of the great malleability of developing sensory systems, there is little known about the effect of nerve lesions on cortical output systems and on the organization of the motor system. Early peripheral nerve lesions may initiate adaptive or compensatory mechanisms in the motor system: these could be revealed as changes in MI representation patterns.

In the simplest sense, MI can be defined as the cortical area in which movements are evoked at the lowest levels of electrical stimulation, although a full definition of MI must include other 
features, such as neuronal discharge properties and connectivity patterns. In rats and other mammals that have been studied, MI is topographically organized, its output neurons project densely to subcortical motor control structures, MI neurons participate in the initiation and control of muscle force, and $\mathrm{MI}$ is necessary for the independent use of muscles in skilled voluntary movements (Evarts, 1981; Neafsey et al., 1986; Wise and Donoghue, 1986). Thus, the consequences of peripheral nerve lesions in the rat MI should provide general insights into the role of $\mathrm{MI}$ in both movement control and recovery from damage that disrupts normal movements. In the present study, we have examined the representation patterns that develop in MI following destruction of the forelimb sensory and motor nerves by amputation on the first postnatal day. It was reasoned that a developmentally early lesion of sensory inputs and motor target structures would reveal the maximum potential of nerve injury to producc an effect upon motor cortical organization.

A preliminary report of portions of these data has appeared elsewhere (Donoghue and Sanes, 1987).

\section{Materials and Methods}

Animals and general surgical procedures. Albino rats (Sprague-Dawley) of both sexes were used in these experiments. Rat pups less than $24 \mathrm{hr}$ old were removed from their dam and werc ancsthetized by cooling them on ice for 5-10 min. Using aseptic procedures, the nerves of the right brachial plexus and the adjacent vessels were ligated using 6-0 surgical suture (ethylon) to prevent regeneration and were cut at the level of the shoulder joint. Muscles around the shoulder were bisected as they crossed the joint between the humerus, scapula, and clavicle, and then the right forelimb was removed. The skin and underlying tissue were closed with 6-0 suture, and the pups were warmed on a heating pad. At the end of the surgical procedure, all pups were returned to the dam and reared according to conventional procedures. One set of control pups was anesthetized, warmed, and returned to the litter. Other controls consisted of normal adults rats. Because there were no readily apparent differences between MI maps obtained from these 2 control groups, they were considered together as "normals."

At 2-4 months of agc, the experimental and normal rats were preparcd for acute mapping procedures, which have been described previously (Donoghue and Wise, 1982). Briefly, animals were anesthetized with an intraperitoneal injection of ketamine $\mathrm{HCl}(100 \mathrm{mg} / \mathrm{kg}$, initial dose) and mouted in a Kopf stereotaxic frame. Supplemental injections of ketamine $\mathrm{HCl}$ (5-10 mg, i.m. or i.p.) were administered when required to suppress hindlimb withdrawal to a firm pinch. Mapping sessions lasted for up to $7 \mathrm{hr}$. Rectal temperature was monitored and stabilized at 37$38^{\circ} \mathrm{C}$ using a hot water heating pad. The left frontal cerebral neocortex was exposed by making a craniotomy that extended from about $2 \mathrm{~mm}$ posterior and $5 \mathrm{~mm}$ anterior to bregma and from 1 to $5 \mathrm{~mm}$ lateral from bregma. The dura was left intact and the cortical surface was covered with $2 \%$ agar dissolved in $0.9 \%$ saline.

Microstimulation mapping. Movements evoked by intracortical electrical stimulation were mapped in the frontoparietal region of the ccrebral neocortex in 13 normal adult rats and in 11 adult rats with a neonatal right side forelimb amputation. Mapping was carried out using procedures that have been described earlier (Donoghue and Wise, 1982; Donoghue and Sanes, 1987). Glass-insulated PtIr electrodes ( $5 \mu \mathrm{m}$ tips, 1-2 $\mathrm{M} \Omega$ impedance measured at $1 \mathrm{kHz}$ ) were used for microstimulation. Electrodes were lowered to $1.8 \mathrm{~mm}$ below the cortical surface and then, while stimulating, they were adjusted up or down a maximum of 200 $\mu \mathrm{m}$ to find the site for the lowest threshold of electrical stimulation to evoke movement. This procedure was used to correct for tissue compression and regional variation in cortical thickness. The electrode depth was verified by direct measurements in histological sections using marking lesions that were placed at some stimulation sites. Confirmation of these laminar effects has been reported and discussed (Donoghue and Wise, 1982; Welker et al., 1984). Electrode penetrations werc spaccd 100-500 $\mu \mathrm{m}$ apart.

For intracortical electrical stimulation, current trains $(30 \mathrm{msec} \mathrm{du}-$ ration, $300 \mathrm{~Hz}, 200-\mu \mathrm{sec}-$ long monophasic, cathodal pulses) of 5-60 $\mu \mathrm{A}$ were passed through the electrode at $1.2 \mathrm{sec}$ intervals. At each penetra- tion sitc, all body parts that were activated at $60 \mu \mathrm{A}$ were identified by a combination of visual inspection and muscle palpation. Tactile stimulation or passive movement of the limb prior to a cortical stimulus volley lowered the threshold for movement. Since these forms of manipulation could not be delivered in a controlled manner, thresholds were determined only after waiting more than $10 \mathrm{sec}$ after any peripheral stimuli were delivered. Then, the current intensity was decreased and the threshold for movement of each body part was noted. Identical procedures were used for mapping MI of normal and experimental animals. Two individuals were required for threshold determination. One observed the movements without detailed knowledge of the actual current intensity. The other individual changed the current level, using the descending method of limits, with $\sim 2 \mu \mathrm{A}$ decrements and with $\sim 20 \%$ catch trials, until the movement examiner reported a $50 \%$ occurrence of movement with repctitive stimulation. The sccond then recorded this current as "threshold" for that particular movement. Occasionally, currents up to $100 \mu \mathrm{A}$ were passed through the electrode to verify a negative site and to examine the effects of current spread. However, currents above $60 \mu \mathrm{A}$ are thought to produce tissue damage (Stoney et al., 1968) and, therefore, were used infrequently. Negative sites were classified as those not eliciting movement at a stimulation current of $60 \mu \mathrm{A}$. If 3 negative sites were recorded in succession within the presumed region of $\mathrm{MI}$, the electrode was returned to a region between 2 previously positive sites and within $100-200 \mu \mathrm{m}$ of one of them. If this site was negative, the experiment was terminated, and all sites after the last recorded positive site were not considered for analysis. These criteria for mapping allowed examination of 28-111 (mean, 57) sites in individual rats. At the end of each experiment, lesions were made at selected sites by passing $10 \mu \mathrm{A} \mathrm{DC}$ for $10 \mathrm{scc}$.

Receptive-field mapping. Standard extracellular recording techniques were used to identify the receptive-field properties of neurons in the region of the SI-MI overlap zone and in the adjacent parts of SI in 3 experimental and 3 normal rats. Rats were anesthetized with urethane $(1.5 \mathrm{gm} / \mathrm{kg}$, i.p.) and a craniotomy was made above SI, following the same procedures described above for stimulation experiments. Neural activity was recorded with glass-insulated PtIr electrodes having impedances of $0.8-1.5 \mathrm{M} \Omega$ at $1 \mathrm{kHz}$. Cutaneous receptive fields of small clusters of neurons in the region of layer IV (around $800 \mu \mathrm{m}$ below the cortical surface) were defined by using light tactile stimuli delivered manually to the body surface with a fine-tipped probe. Two to three marking lesions were placed at the end of the recording sessions.

Perfusion and histological preparation. At the conclusion of a stimulation or a recording experiment, the animal was injected with an overdose of sodium pentobarbital and perfused intracardially with $0.9 \%$ saline, followed by $10 \%$ formol saline. Sections of the brain and the spinal cord were cut in the frontal plane at $50 \mu \mathrm{m}$ on a freezing microtome, stained with thionin using routine procedures, and compared microscopically.

Reconstruction of electrode penetrations. The locations of stimulation, recording, and lesions sites were marked on line drawings of histological sections using a drawing tube attached to a microscope. The location of electrode tracks that could not be visualized was determined by extrapolating from penetration coordinates and marking lesions that were confidently identified.

Map construction. Results of the mapping experiments were plotted in a series of cortical surface maps that illustrated the location of each electrode penetration and somatotopic organization. For low-threshold maps, the area of a body part representation was defined as the region that enclosed the cortical area from which movement of that body part was evoked at the lowest current intensity. Map borders were defined as the midpoint between penetrations evoking movements of 2 separate body parts (e.g., vibrissa and forelimb) at the lowest threshold. However, boundaries were drawn through points at which movement of 2 body parts were evoked at similarly low thresholds (within $\pm 1 \mu \mathrm{A}$ of the lowest threshold movement at that site) unless the points were separated by more than $1 \mathrm{~mm}$. In these cases, boundaries were drawn $250 \mu \mathrm{m}$ from the data point. Boundaries between SI and the rostrally located lateral agranular cortical field $\left(A G_{1}\right)$ and between $A G_{1}$ and the adjacent medial agranular field $\left(\mathrm{AG}_{\mathrm{m}}\right)$ were obtained from the histological sections using the architectonic features described by Donoghue and Wise (1982). Maps of the total representation of a particular body part were constructed by plotting all points from which movements of this part were evoked at or below $60 \mu \mathrm{A}$. The size, shape, and location of maps, movement thresholds (in $\mu \mathrm{A}$ ), and types of movements evoked at stimulation sites in and around the presumptive forelimb zone were com- 
pared to those of normal rats. Sizes of representations were measured using the Bioquant software package implemented on an Apple II computer.

\section{Results}

\section{General topography and thresholds of normal MI}

Movements were evoked by intracortical electrical stimulation in the region of $\mathrm{MI}$ at 653 of 786 sites $(83.1 \%)$ tested in 13 normal animals. A general schematic of the somatic representation pattern of the rat MI is shown in Figure 1, and representative MI maps generated from 2 normal rats in this study are shown in Figure $2 A$. These maps depict the areas from which movements of particular body parts are elicited at the lowest levels of electrical stimulation. The schematic map is included to illustrate the general location, the topographic relationships, and the relative size and variability of the somatic components of MI representations based on results in normal animals.

The general features of the size, shape, and location of MI in the rats examined here conform to previous descriptions (Hall and Lindholm, 1974; Donoghue and Wise, 1982; Neafsey and Sievert, 1982; Sanderson et al., 1984; Neafsey et al., 1986). The area of MI defined by electrical stimulation is largely comprised of the cytoarchitectonically distinct $\mathrm{AG}_{1}$. Most of $\mathrm{MI}$ is occupied by areas from which forelimb and vibrissa movements can be evoked (Fig. 2). The hindlimb, trunk, and other body part representations constitute the remaining area. The forelimb and vibrissa areas are elongated in the rostrocaudal dimension, and these 2 areas share a long, common border. A portion of the immediately adjacent granular SI is also included within MI, since electrical stimulation in this region evokes movements at thresholds comparable to those in the agranular part of MI (Hall and Lindholm, 1974; Donoghue and Wise, 1982; Sanderson et al., 1984). The entire MI distal hindlimb representation and the caudalmost part of the forelimb representation are contained within this MI-SI overlap zone (Hall and Lindholm, 1974; Donoghue and Wise, 1982; Sanderson et al., 1984). The caudal and caudolateral areas of MI are bordered by areas of SI from which movements are not evoked at $\leq 60 \mu \mathrm{A}$ (negative sites in Figs. 2-4) in anesthetized animals (Donoghue and Wise, 1982; Hummelsheim and Wiesendanger, 1986).

In the normal rat, the forelimb area was defined as the region within MI that included all sites from which contralateral or ipsilateral movements about the shoulder, elbow, wrist, or metacarpophalangeal joints were evoked at threshold currents. Movements about the elbow, wrist, and digits were collectively termed distal forelimb movements. Most commonly, threshold electrical stimulation produced elbow flexion, wrist extension, or digit extension. Movements about the shoulder joint, termed proximal forelimb movements, included extension or, less frequently, abduction of the forelimb. In the normal rat, the proximal forelimb representation was located almost entirely within the distal forelimb area, since proximal movements were nearly always evoked at distal forelimb sites only when the stimulation intensity was increased (Fig. 3). From a total of 66 points from which shoulder movements were evoked, a distal forelimb movement was the lowest threshold movement at 56 of these points. At one shoulder site, elbow flexion was evoked at the same low threshold current required to evoke shoulder movements. At the 9 remaining sites, shoulder movements were evoked independently of distal forelimb movements, but in conjunction with other movements, especially of the neck and trunk. No sites were found in the normal rats from which both

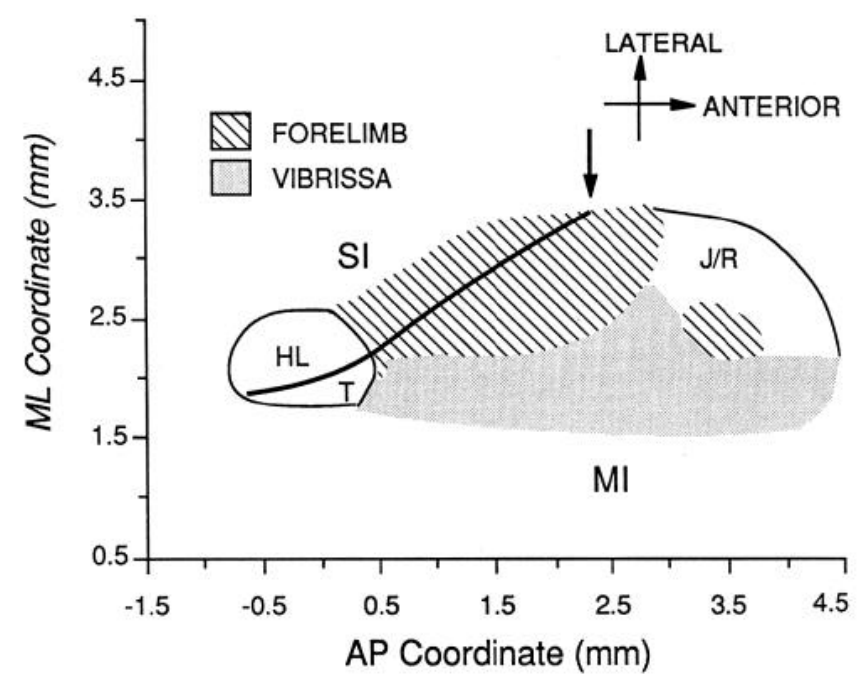

Figure 1. Somatotopic representation pattern in MI. The "typical" location and topological relationships of the representation of body parts relevant to these experiments are illustrated. This generalized schematic incorporates the results of mapping studies in normal animals (see text). The solid line that traverses MI in a posteromedial direction demarcates the boundary of $A_{G_{1}}$ with the granular SI cortex. All of the distal hindlimb $(H L)$ and a portion of the forelimb representations are located within a part of granular SI cortex called the overlap zone. Cells in the granular cortex respond to somatic sensory stimulation, whereas cells in the agranular cortex are driven weakly or not at all by these stimuli (Welker et al., 1984; Donoghue, 1985). $J / R$, jaw/nose; $T$, trunk.

shoulder and distal forelimb movements were evoked and where the shoulder movement had a lower threshold current than that needed to evoke the distal forelimb movement. The mean threshold needed to evoke shoulder movements with intracortical stimulation $(42.35 \pm 1.61 \mu \mathrm{A}$, mean $\pm \mathrm{SEM} ; n=66)$ was significantly higher than the currents needed to evoke distal forelimb movements $(29.6 \pm 0.61 \mu \mathrm{A} ; n=510 ; p \leq 0.0005$; 2 -tailed $t$ test). By comparison, the mean threshold for vibrissa movements $(30.8 \pm 0.88 \mu \mathrm{A} ; n=250)$ was not significantly different from the threshold for distal forelimb movements.

\section{Extent of the MI body representation in normal and experimental rats}

The ability of stimulation to evoke movements was tested at 580 sites in 11 neonatally amputated rats. Movements were evoked from $428(82.3 \%)$ of these sites. Examples of low threshold maps of experimental rats are shown in Figures $2 B$ and 4 . The first notable feature of these maps is that the distribution of sites from which movements of any body part are evoked is similar to that observed in normal animals. Thus, we did not observe large areas from which movements could not be evoked, but, instead, stimulation produced movements over a contiguous region within the lateral agranular cortex.

The forelimb region in amputated rats was defined as the area from which either shoulder or ipsilateral forelimb movements could be evoked at the lowest threshold current intensity. In experimental animals, stimulation in the more caudally located regions of the forelimb representation of normal rats resulted in low threshold movements of the shoulder and ipsilateral forelimb (Figs. 2B, 3, 4). The composite size of the MI shoulder and ipsilateral forelimb areas in experimental rats was significantly smaller, by $47 \%$, than the total size of the low threshold forelimb area in normal rats (normal, $3.93 \pm 0.38 \mathrm{~mm}^{2}$; ex- 

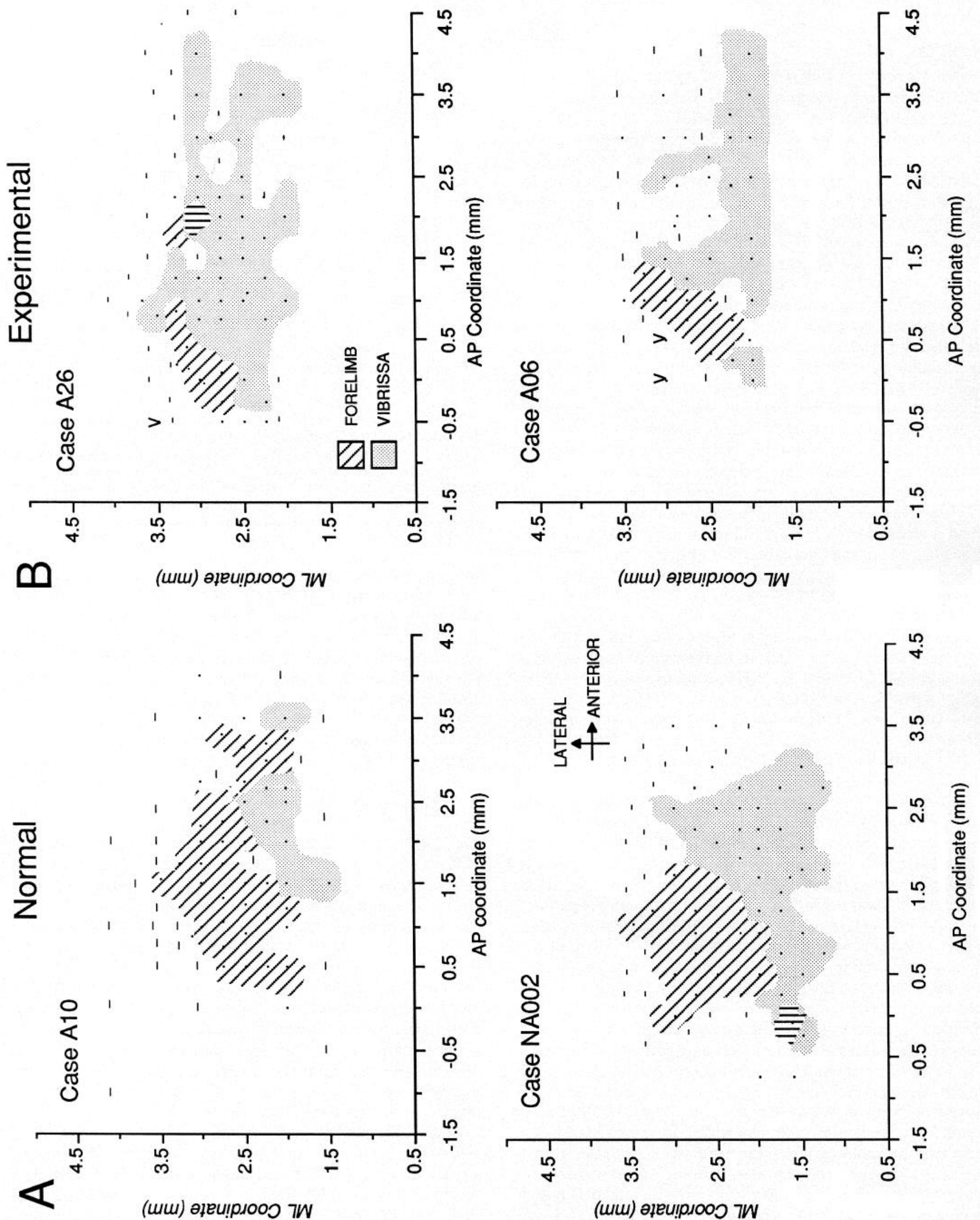

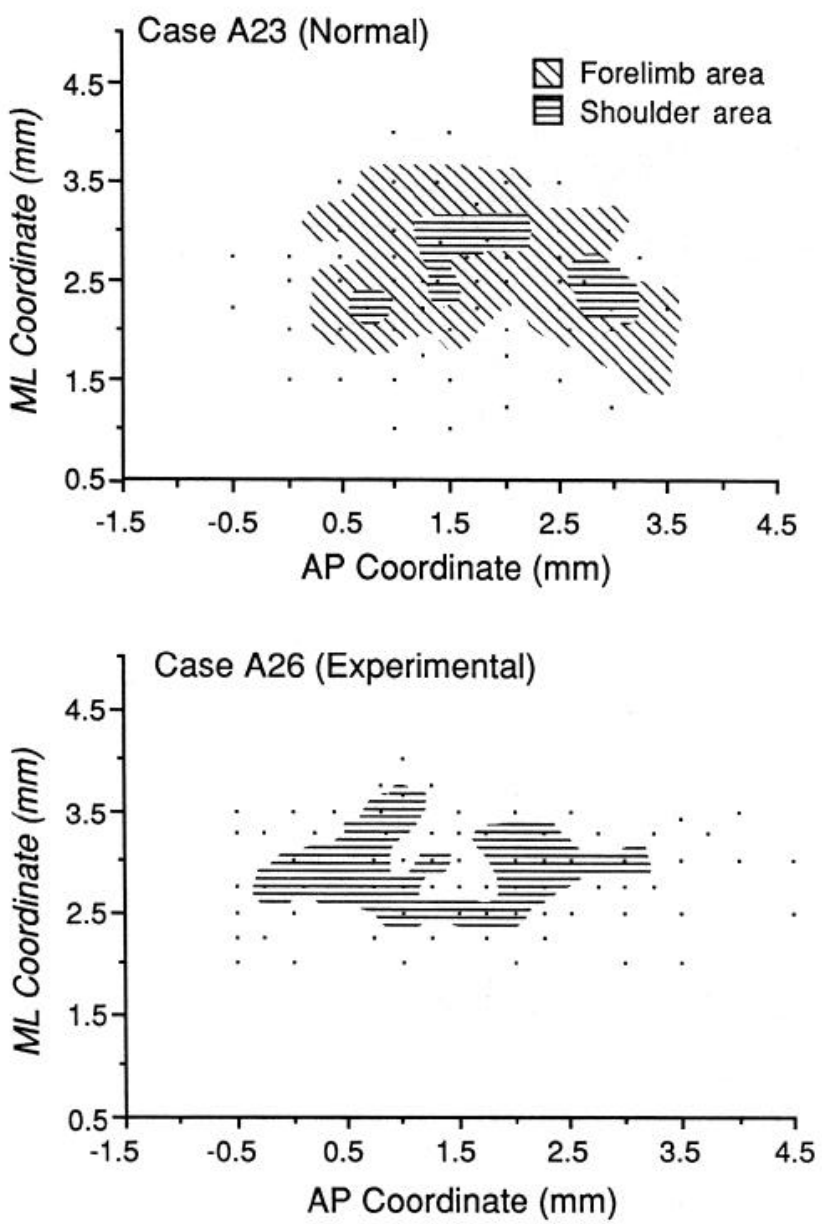

Figure 3. Shoulder representations in a normal and an experimental rat. In the normal animal (A23), the shoulder representation is contained entirely within the low-threshold distal forelimb area. All shoulder movements in this animal were evoked at sites from which a distal forelimb movement was evoked at a lower current intensity. Note that the shoulder representation is not contiguous. In the experimental animal (A26), the shoulder zone was larger than that seen in normal rats and was topographically contiguous.

perimental, $\left.1.86 \pm 0.38 \mathrm{~mm}^{2} ; p \leq 0.0025\right)$. However, the region from which shoulder movements could be evoked was 2.56 times larger in experimental rats ( $p \leq 0.005$; Fig. 5), indicating that a greater-than-normal extent of MI cortex was dedicated to the control of shoulder muscles in the experimental rats.

While forelimb movements were always elicited at low thresholds in SI adjacent to the agranular cortex in normal rats, it was typically not possible to evoke activity from the extant shoulder or ipsilateral distal forelimb musculature by stimulating within any part of SI of experimental animals (Figs. $2 B, 3,4$ ). Thus, in experimental rats, the location of the caudal MI border, as determined by electrical stimulation, corresponded to the cytoarchitectonic border between the $\mathrm{AG}_{1}$ and the granular SI
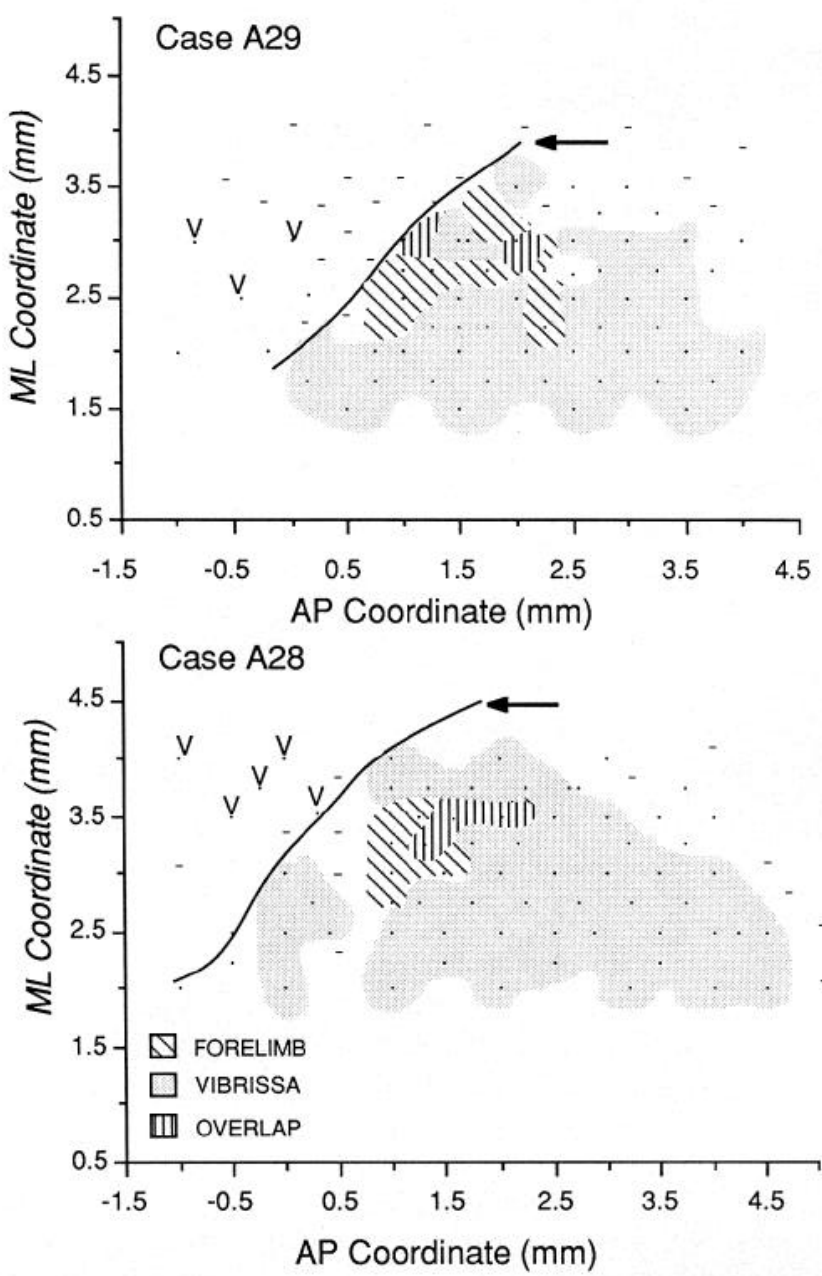

Figure 4. Low-threshold MI maps from 2 experimental rats. These maps illustrate the large vibrissa representation (stippled area) commonly found in MI following neonatal forelimb amputation. Shoulder and ipsilateral forelimb (slanted hatching) movements were evoked from only a small region of cortex. Vertical hatching depicts areas from which vibrissa and forelimb movements were evoked at the same low-intensity current. The nearly total envelopment of the forelimb zone by the vibrissa representation in case A28 (and somewhat in case A29) was never observed in normal rats. In these 2 animals, vibrissa movements were also evoked by stimulating in the granular portion of MI. The solid line indicated by the arrow signifies the border between $\mathrm{AG}_{1}$ anteriorly and SI posteriorly.

cortex. In 5 of 11 cases, stimulation in SI did, however, produce vibrissa movements at thresholds that were comparable to those observed in agranular cortex. The most dramatic example of this was seen in case A28 (Fig. 3), in which stimulation at 5 sites produced vibrissa movements. In the normal rat, vibrissa movements were not evoked by stimulation in the part of SI near agranular cortex, although these movements can occasionally be evoked at some sites in the SI vibrissa area of normal

Figure 2. Low-threshold MI maps. Cases A10 and NA002 (A) are normal rats and cases A26 and A06 (B) are experimental rats. Each dot in these maps indicates an electrode penetration site from which movement was evoked at $\leq 60 \mu \mathrm{A}$; dashes mark negative sites. All low threshold vibrissa sites are enclosed by stippling and forelimb sites are enclosed by slanted hatching. Vertical stripes mark areas from which forelimb and vibrissa movements were evoked at the same current intensity. Movement of other body parts was evoked at unlabeled sites. Note that the forelimb representation is smaller and vibrissa sites are found more laterally in MI of experimental rats (see also Fig. 4). In these 2 experimental rats, vibrissa movements were elicited in the granular cortex $(V)$. 


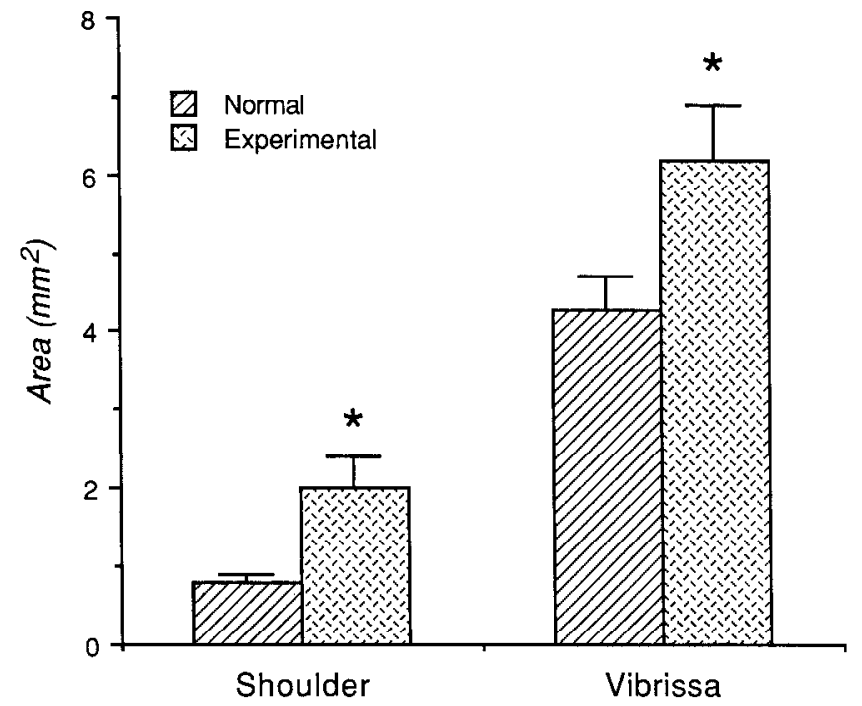

Figure 5. Sizes of the shoulder and vibrissa representations in normal and experimental rats. The aggregate area of the shoulder and vibrissa representations was derived using the low-threshold sites for the vibrissa representation and any movement occurrence at stimulation currents $\leq 60 \mu \mathrm{A}$ for the shoulder sites. The size of both the shoulder and vibrissa representations increased following neonatal forelimb amputation.

rats (Sapienza et al., 1981). IIindlimb movements were evoked within the expected region of SI (Hall and Lindholm, 1974; Donoghue and Wise, 1982), at thresholds similar to that observed in the normal rat, indicating that this portion of the overlap zone had developed normally. The hindlimb area was not mapped in sufficient detail to measure its size.

In addition to the larger-than-normal MI shoulder area, the size of the vibrissa representation was also increased by $44 \%$ in experimental animals ( $p \leq 0.05$; Fig. 5). It appeared that this increase could be accounted for principally by the occurrence of sites from which vibrissa movements could be evoked further laterally than was commonly observed in normal rats (Figs. 2, 4,6 ). This observation held despite the finding that the greatest number of sites from which vibrissa movements could be elicited was located at the same distance from the midline-that is, the coordinates $1.76-2.25 \mathrm{~mm}$ lateral to the midline-in both cxpcrimental and normal rats. The comparison illustrated in Figure $6 \mathrm{~B}$ shows that the current intensity required to evoked vibrissa movements from the more laterally shifted sites in experimental animals was comparable to that observed in the core of the vibrissa region of normal and experimental rats.

\section{Movement thresholds in normal and experimental rats}

Thresholds to evoke movements were compared between the 2 groups of rats. For the total number of sites examined, movements were evoked at the same mean low threshold current in experimental $(27.69 \pm 0.74 \mu \mathrm{A})$ and normal $(28.28 \pm 0.51 \mu \mathrm{A})$ rats. Despite the similarity in the low threshold currents for the accumulated body parts, there were differences in the currents required to activate individual body parts between the 2 groups of rats. This was analyzed by comparing the currents needed to evoke vibrissa, shoulder, and ipsilateral distal forelimb movements (Fig. 7A). Thresholds for proximal forelimb or vibrissa movements were significantly lower in the experimental than in the normal rats ( $p \leq 0.0005 ; 2$-tailed $t$ test). The decrease in stimulation thresholds necessary to evoke contralateral shoulder movements in experimental rats is further illustrated in Figure
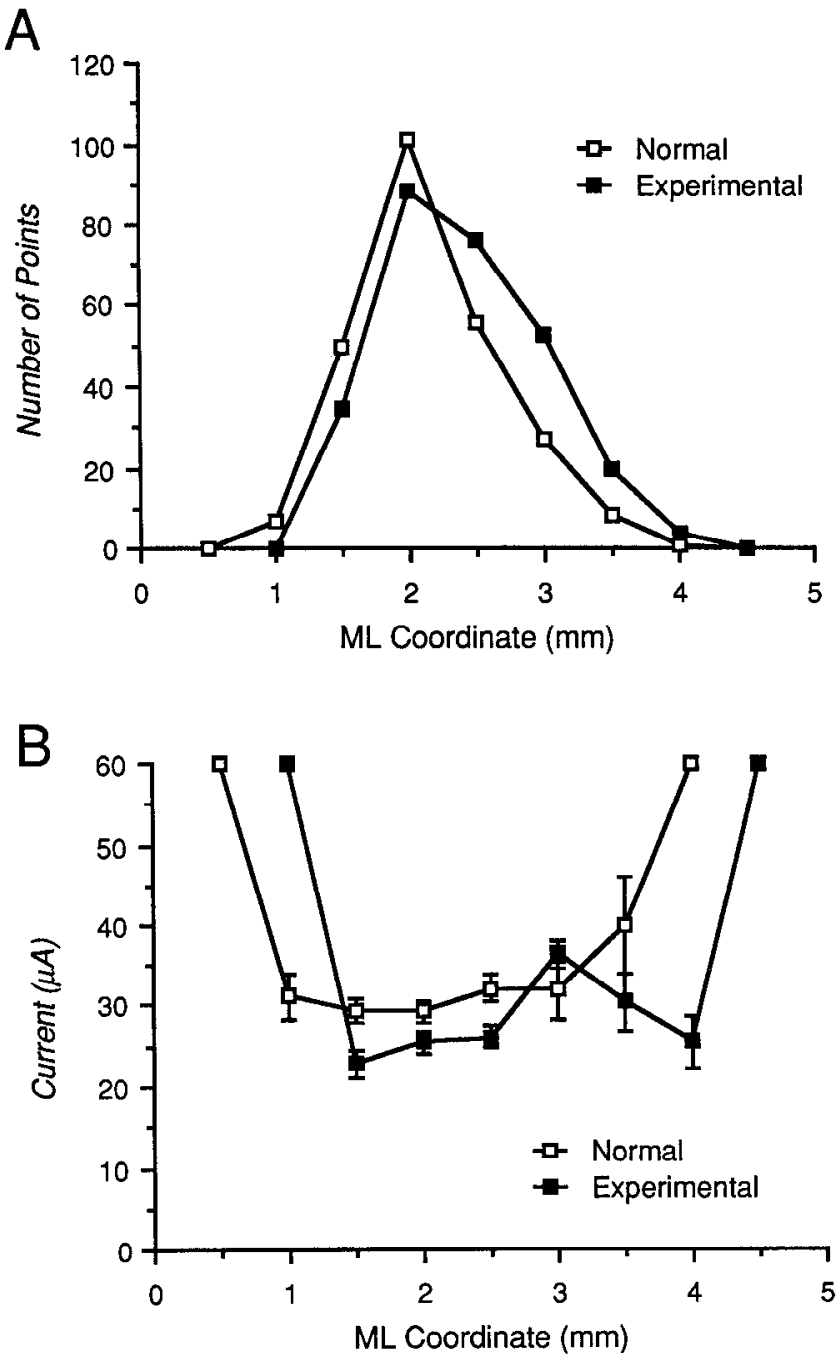

Figure 6. Mediolateral frequency and current intensity distribution of vibrissa points. $A$, Increase in the number of vibrissa points in lateral parts of MI in experimental rats. The total number of vibrissa sites, binned to contain all data collected over each $0.5 \mathrm{~mm}$ interval of cerebral cortex between 0.5 and $4.5 \mathrm{~mm}$ lateral from the midline, is shown for normal and experimental rats. Vibrissa sites were collapsed in the anterior-posterior dimension for $A$ and $B$. The peak number of vibrissa points for both groups of rats is between 1.76 and $2.25 \mathrm{~mm}$ lateral from the midline. More sites are observed laterally in the experimental than in the normal rats. $B$, Similarity of stimulation thresholds throughout mediolateral extent of MI vibrissa area. The average threshold currents required to evoke vibrissa movements are displayed for each $0.5 \mathrm{~mm}$ of cerebral cortex from 0.5 to $4.5 \mathrm{~mm}$ lateral from the midline. In the central portions of the vibrissa representation (except at $3.0 \mathrm{~mm}$ ), the average currents required to evoke vibrissa movements were lower in experimental animals. In the lateralmost sections of the vibrissa representation of experimental rats, the average currents for vibrissa movements were not different from those observed in the central regions of the vibrissa representation.

$7 B$, in which the number of electrode penetrations from which shoulder movements could be evoked is shown with respect to the threshold current. Two features are noteworthy in this illustration. First, the median current required to evoke shoulder movements is lower in experimental $(38 \mu \mathrm{A})$ than in normal $(45 \mu \mathrm{A})$ rats. Second, the total number and frequency of shoulder sites is greater in the group of experimental animals ( $n=140$; $12.73 /$ case) than in the group of normal rats $(n=66 ; 5.08 /$ case). If the incidence of shoulder movements in experimental animals 

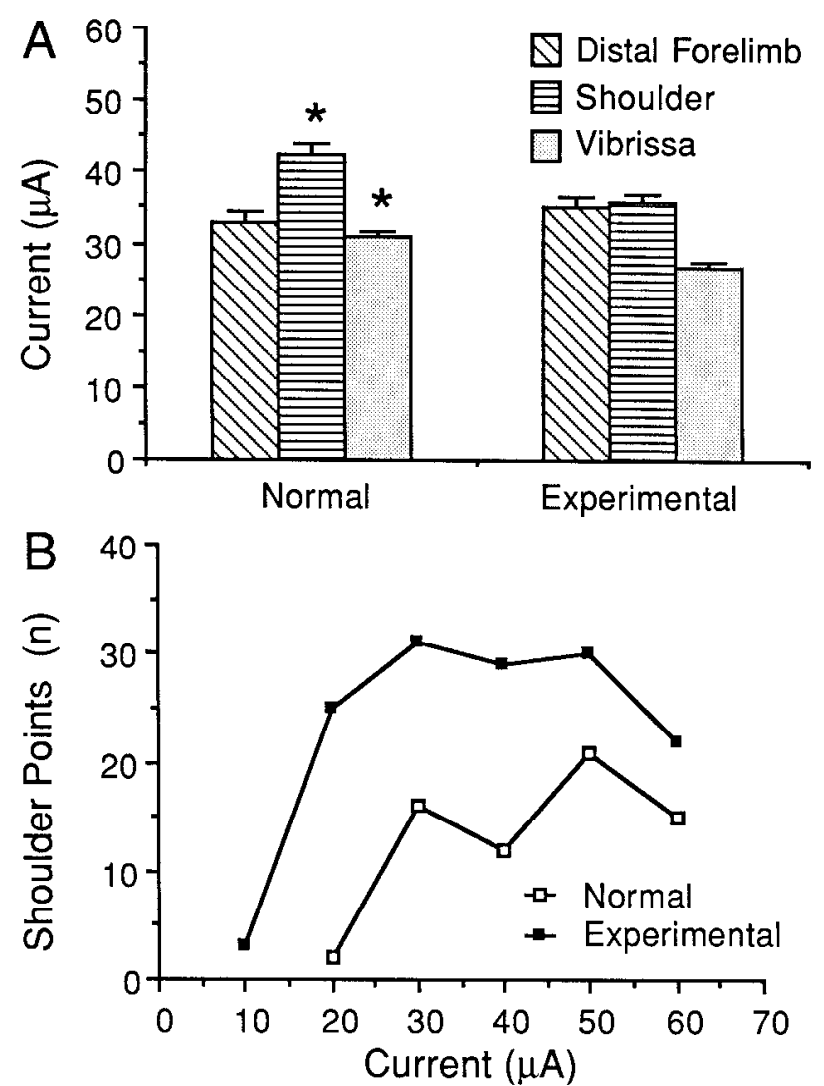

Figure 7. Threshold comparisons and number of shoulder points. $A$, Comparison of movement thresholds in normal and experimental rats. The average threshold current $( \pm$ SEM) required to evoke either the distal ipsilateral forelimb, shoulder, or vibrissa movements in both groups of rats is displayed. The mean current required to evoke shoulder or vibrissa movements decreased following neonatal forelimb nerve transection, whereas there was no change in current thresholds required to produce ipsilateral distal forclimb movements. $B$, Lower current intensity required to evoke shoulder movements in experimental rats. The number of points where shoulder movements were observed in each $10 \mu \mathrm{A}$ bin between 0 and $60 \mu \mathrm{A}$ is shown for normal and experimental rats. A larger number of shoulder points were found in experimental rats, and, in these rats, a greater proportion of the shoulder sites had current thresholds below $30 \mu \mathrm{A}$.

is normalized with respect to the total number of penetrations in experimental and normal rats, then shoulder movements were found at $24.14 \%$ of the sites in experimental rats and $8.4 \%$ of the sites mapped in normal rats.

Stimulation throughout MI in experimental animals produced movements of the ipsilateral forelimb at an incidence that was not different from that in normal rats. In the experimental rats, ipsilateral distal forelimb movements were observed at 54 of 156 sites, from which either a proximal or an ipsilateral distal forelimb movement was evoked. Stimulation at 29 of these sites evoked only ipsilateral distal forelimb movements, while both contralateral shoulder and ipsilateral distal forelimb movements were evoked at an additional 25 sites. As shown in Figure $7 \mathrm{~A}$, the average threshold for activation of ipsilateral distal forelimb movements was not altered by neonatal forelimb nerve section.

\section{Coincidence of forelimb and vibrissa movements in MI}

Although distinct low threshold forelimb and vibrissa zones exist within MI, it was also possible to evoke movements of

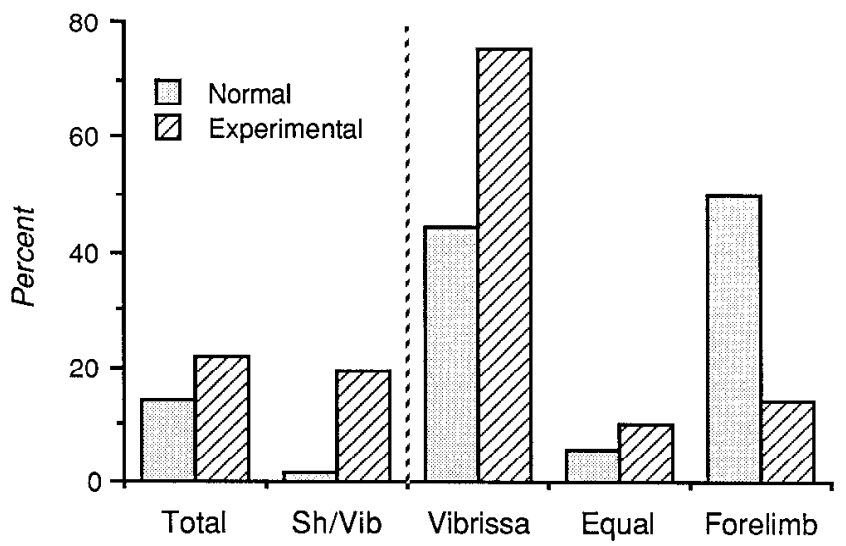

Figure 8. Coincidental occurrence of vibrissa and forelimb movements in MI. The proportion of total sites where forelimb and vibrissa movements were evoked at the same site (left of the dashed vertical line) and relative proportions of these sites having vibrissa or forelimb movement as the lowest threshold (right) is illustrated for normal and experimental rats. The left section shows the percentage of the coincidental occurrence of vibrissa and forelimb movements at a single MI site with respect to the total number of vibrissa and proximal and distal forelimb sites $($ Total , and with respect to the total number of vibrissa and shoulder sites $(S h / V i b)$ in each group of rats. For both comparisons, the proportion of vibrissa and forelimb movements occurring at the same site increased in experimental rats. The right section illustrates the proportion of combined vibrissa-forelimb sites in which vibrissa or forelimb movements had the lower threshold. In normal animals, there was roughly an equal number of these coincident sites that were "dominated" by either vibrissa or forelimb movements. By contrast, in experimental rats, a larger proportion of the combined sites had a lower threshold for vibrissa than for forelimb movement.

both structures at some sites; this relationship was altered by unilatcral amputation. In normal animals, there were 72 sites from which both forelimb and vibrissa movements could be evoked, whereas 76 forelimb-vibrissa-"coincident" sites were identified in experimental animals. Since, in experimental animals, there were fewer sites at which either forelimb or vibrissa movements could be evoked (336, compared to 520 sites in normal rats), there was, therefore, a higher probability that vibrissa and forelimb coincidence would occur in experimental than in normal rats (Fig. 8). At the forelimb-vibrissa-coincident sites in normal animals, it was equally likely that the low threshold movement would be either of the vibrissa or forelimb (Fig. 8 , right section). This pattern of equal threshold distribution was altered in the experimental rats $\left(\chi^{2}=20.8 ; p \leq 0.001\right)$ such that vibrissa movements were the low threshold movement at $76.3 \%$ of these coincident sites. Pairing of shoulder and vibrissa movements at the same current intensity was rare in normal rats (only $1.6 \%$ of all forelimb or vibrissa sites), but was much more common in experimental rats $(19.5 \%$ of all ipsilateral forelimb and contralateral proximal forelimb or vibrissa sites). Movement of the electrode to a new penetration site that was within $300 \mu \mathrm{m}$ of a vibrissa-forelimb-coincident site could result in either a large change in the current required to elicit one of the 2 movements or a complete failure to elicit one or both of the vibrissa or forelimb movements.

\section{Receptive fields in the MI-SI overlap zone}

In normal rats, cells in the MI-SI overlap area have cutaneous receptive fields located on the contralateral distal limb (Sanderson et al., 1984). Since this region lacked the normal distal forelimb somesthetic inputs during development, the type of 

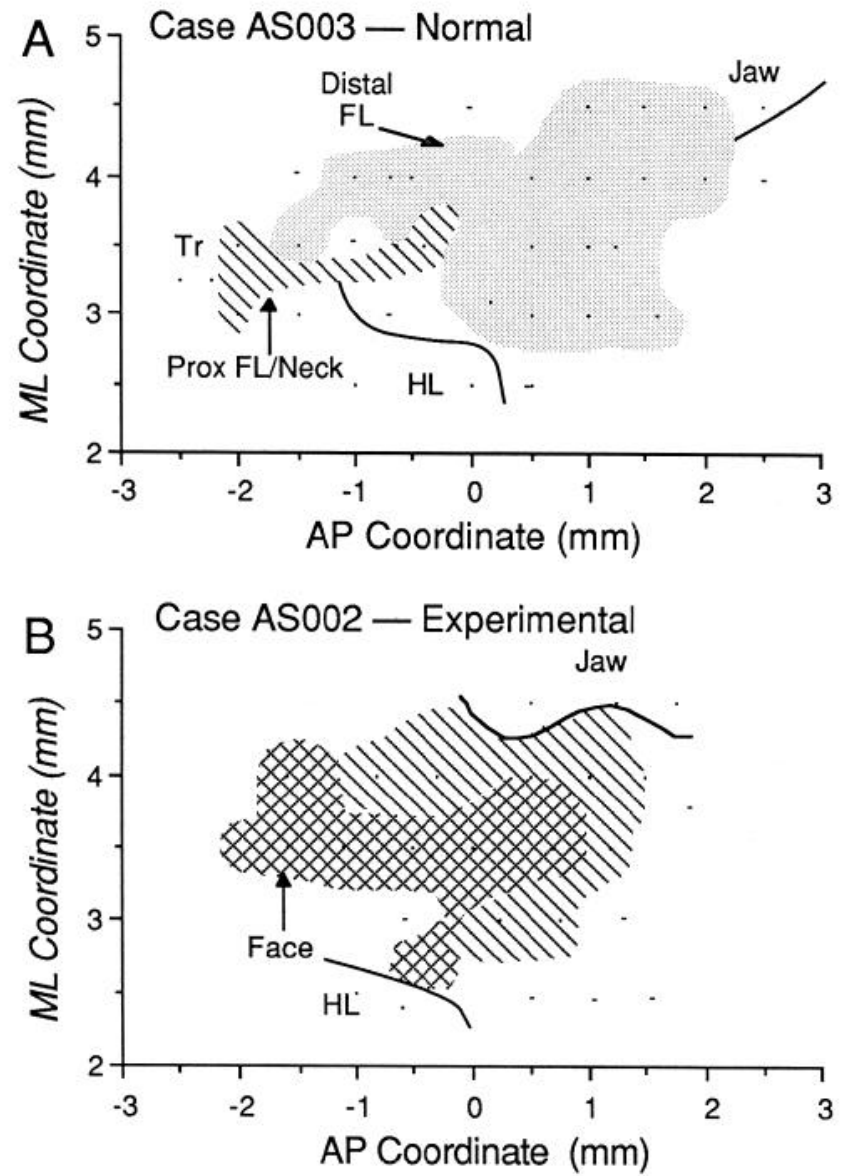

Figure 9. Map of somatic sensory receptive fields in frontoparietal cortex. A, Multiunit receptive-field maps in a normal rat. The stippling encloses all sites for which units could be activated by tactile stimulation of the distal forelimb. Sites where cells were located with receptive fields on the proximal forelimb and neck are indicated by the oblique hatching. Other sites are marked with a dot if cells had receptive fields on the hindlimb $(H L)$, trunk $(T r)$, or jaw, or by a dash if receptive fields could not be identified. The coordinate system is the same as for stimulation maps. $B$, Receptive-field map in an experimental rat. Cells in the same general location of the forelimb area of normal rats are activated by light tactile stimulation of the proximal forelimb/neck or face (crosshatches). Note that the hindlimb and jaw representations have roughly the same positions in control and experimental rats.

sensory information that activated cells in this area could have influenced the output organization of this cortical area. To explore the nature of sensory input to this region, somatosensory receptive fields were studied with single and multiunit recording techniques in 3 normal and 3 experimental rats. In normal rats (Fig. $9 A$ ), cells in SI near the $\mathrm{AG}_{1}$ have receptive fields on the contralateral distal forelimb. Cells recorded from experimental rats (Fig. 9B) throughout the granular area of SI, including the region of the normal forelimb representation, were readily activated by light tactile stimuli on the contralateral body surface. In experimental rats, cells in the area where the distal forelimb representation normally develops had receptive fields on the shoulder, trunk, or face. Cells with receptive fields on these body parts could also be found in their usual locations in the other parts of SI. Thus, in experimental rats, the presumptive distal forelimb area of SI appeared to be included in the enlarged cortical representations of other body parts. It was difficult to identify receptive fields for cells located in the adjacent agranular cortex in either normal or experimental rats.

\section{Anatomical consequences of forelimb removal}

Thionin-stained sections of brain and spinal cord were examined for cytological effects of forelimb amputation. Several distinct anatomical alterations were observed in the brain stem and spinal cord of experimental rats. Figure 10 shows a section from the cervical spinal cord of an animal that had one forelimb removed at birth. The darkly staining motor neurons in the ventral horn observed on the intact side (Fig. 10, left) are markedly reduced in number on the side ipsilateral to the lesion. Motor neurons were counted in several sections through both sides of the cervical enlargement from each of 3 experimental rats. The average number of cells in the ventral horn of the normal side was $30.4 \pm 1.7$, and in the experimental side it was $17.5 \pm 2.1$ cells. This represents a $57.6 \%$ reduction of large neurons on the side of the amputation. Distal motor neuron pools located dorsolaterally appear to be largely absent, while pools for proximal muscles appear to be relatively intact. Reduction in the size of the cuneate fasciculus (Fig. 10) and nucleus (not shown) ipsilateral to the amputation is also evident in these animals. Sections through MI showed no obvious alterations in cytoarchitectonic patterns or in the overall size of MI.

The apparent increase in the area of the vibrissa representation at the expense of the distal forelimb representation, and the loss of spinal targets suggested that corticofugal neurons may have shifted their connections with the spinal cord to brain stem areas related to vibrissa movements. This was evaluated by labeling corticospinal neurons with injections of HRP into the corticospinal tract at the cervical level. Although a shift from forelimb to vibrissa control might suggest that labeled cells were restricted to a smaller cortical area, reconstruction of these cases indicated that there was no difference in the labeling pattern of corticospinal neurons between normal and experimental rats.

\section{Discussion}

These experiments demonstrate that the rat MI representation pattern develops novel organizational features after forelimb amputation on postnatal day 1 . Electrical stimulation mapping in MI revealed that, in experimental rats, (1) the current intensities required to evoke shoulder movements are lower; (2) the size of the vibrissa and shoulder representations are larger; (3) vibrissa movements are more frequently coupled with shoulder movements than in normal rats; and (4) proximal or ipsilateral forelimb movements are not elicited from SI within the area examined. Collectively, these findings indicate that the amount of MI cortex allocated to the control of a set of muscles can be changed by peripheral nerve injury, and that some ordinarily segregated output functions of MI may be combined into a single cortical area. In addition to these new findings concerning MI, these results confirm previous reports in rats that neonatal nerve injury alters somatic sensory representation patterns in SI.

\section{Microstimulation as a means for assessing MI representation pattern}

The alterations in MI observed here are based on maps generated by observing movement patterns during electrical stimulation of the cortex. Deviations from the normal pattern, size, or threshold of stimulation effects are interpreted as a change in the functional representation of muscles in MI. This mapping 


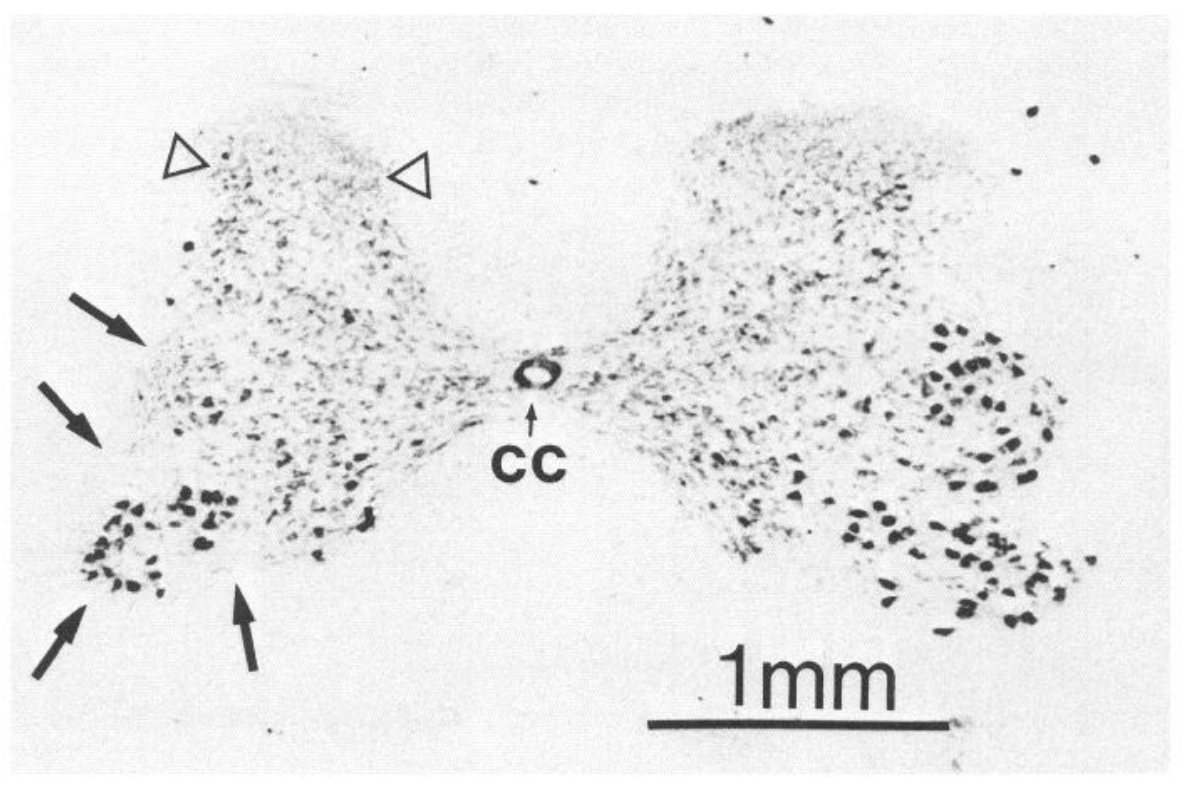

Figure 10. Transverse section of cervical spinal cord from a neonatally amputated rat. Note the marked numerical reduction of large, darkly staining ventral cells ipsilateral (arrows at left) to the nerve lesion. The arrows at the bottom that point upwards indicate intact motor neuron pools. The open arrowheads surround the shrunken dorsal horn ipsilateral to the nerve lesion. Thionin stain. technique shows that shifts in the location of microelectrode penetrations as small as $100 \mu \mathrm{m}$ can change the body part that moves at the lowest stimulation intensity. This seems to suggest that electrical stimulation affects only a nearby, small group of cells. Higher current intensities would produce other movements by recruiting cells with higher thresholds or those at a distance through current spread (Stoney et al., 1968). However, it has been shown that single-pulse epicortical electrical stimulation may produce synaptic activation of cortical neurons over areas on the order of $2 \mathrm{~mm}$ (Ezure and Oshima, 1985). Thus, the movements evoked from stimulation of MI are not necessarily related only to direct local activation of pyramidal tract neurons, but are probably due both to direct activation and a pattern of synaptic activation from stimulation of a cortical locus. Shifting the stimulation location to a nearby site would then activate a set of neurons that may largely overlap those that were activated from the former site, but the net change in the activation pattern is sufficient to produce a different movement. That stimulation-evoked movements are largely mediated by corticospinal projections is demonstrated by the finding that electrically evoked movements are found less frequently and occur at higher current intensities after section of the pyramidal tract (Woolsey et al., 1972; Mitz and Humphrey, 1986). While the intracortical pattern of activation by electrical stimulation remains to be determined, shifts in this pattern following neonatal forelimb amputation are clearly revealed by this method: threshold relationships, size of representation, and muscle groupings are all abnormal after this manipulation.

It would be useful to know whether these electrical stimulation effects are related to the functional role of a cortical area. Although electrical stimulation most likely produces unnatural patterns of activation, the correspondence of electrical stimulation effects with neuronal activity in MI of behaving normal animals suggests that the pattern of muscle activity revealed by electrical stimulation at a cortical site is closely related to neural activity in that area (Horne and Porter, 1971; Humphrey and Reed, 1983; Donoghue, 1985; O'Donoghue et al., 1986).

\section{Enlargement of the vibrissa and shoulder representations}

The similarity between experimental and normal rats in the distribution of sites from which movements could be evoked by MI stimulation suggested that some representations expanded into the normal distal forelimb representation. Both the shoulder and vibrissa musculature developed abnormally large representations after neonatal amputation; these expansions were located in the MI region normally occupied by the distal forelimb musculature. This conclusion is based on the findings that the total area of cortex encompassed by sites from which proximal forelimb or vibrissa movements were evoked is larger than comparable areas in normal rats; that this enlargement occurs in the region where the distal forelimb representation is normally present; and that intracortical stimulation is capable of evoking movements in both groups of rats in the same overall percentage of sites. In terms of relative and absolute scales, these changes in area are pronounced. On average, the shoulder develops a representation that is more than $2 \frac{1}{2}$ times the normal size, and the vibrissa area is increased by about one-half (Fig. $5)$. This latter change represents an areal increase of nearly 2 $\mathrm{mm}^{3}$ in the cortical whisker representation. That the vibrissa occupies a larger-than-normal cortical territory in MI of experimental rats is supported by 2 additional observations. First, vibrissa movements could be evoked from sites that were topologically inappropriate for normal animals. In some experimental rats, the vibrissa representation surrounded the proximal forelimb representation laterally and lay adjacent to the posterior-medial MI boundary with SI. These features were never observed in normal rats. Second, both vibrissa and shoulder movements were coupled more frequently at individual MI sites.

The increase in vibrissa-forelimb paired sites in experimental animals did not appear to be due simply to an increase in the shared border between these 2 representations. The presence of larger regions of vibrissa and forelimb overlap (compare Fig. $2 A$ with 4) suggests that an area develops in MI of experimental rats which influences both the vibrissa and shoulder muscula- 
ture. This indicates that nerve lesions may cause regions of MI to develop control over muscle groups that are ordinarily kept separate in MI. Despite this unusual pairing of vibrissa and shoulder muscles, there was relative uniformity in stimulation thresholds and in the movement types elicited throughout the distinct and overlapping vibrissa and shoulder representations. This finding suggests that the overlapping representation has a synaptic relationship to target muscles and subserves functions similar to the distinct part of each representation. Similar arguments obtain for the shoulder representation. The size of the shoulder representation is larger in experimental animals, and the threshold to evoke movements from this area is lower than that in normal rats.

\section{Changes in the strength of connections between motor cortex and muscles}

The lower threshold to evoke shoulder movements in experimental rats suggests that stronger-than-normal synaptic coupling between the motor cortex and proximal motor neurons develops as a consequence of neonatal forelimb amputation. The hypothesis that synaptic strength changes assumes that intracortical electrical stimulation reflects the relative strength of the coupling between a subregion of MI and a specific muscle or muscle group. Alternatively, it is possible that the threshold intensity of electrical stimulation required to activate MI neurons projecting to the shoulder or vibrissa musculature has been lowered by neonatal forelimb amputation. Thus, neurons might be activated more effectively by weak currents at a distance from the stimulating electrode. Both of these mechanisms could produce altered electrical stimulation thresholds. However, the fact that overall electrical stimulation thresholds are similar in normal and experimental rats indicates that the excitability of neurons is about the same in these 2 groups. This result favors the notion that changes in synaptic efficacy at some point in the path to the muscles accounts for the modifications we observed.

Central lesions also appear to be able to alter the relationship between MI and the muscles. Neonatal hemicerebellectomy or unilateral MI lesion decreased the thresholds for activating ipsilateral forelimb musculature from MI, without a noticeable change in the overall MI representation pattern (Kartje-Tillotson et al., 1985; O'Donoghue et al., 1986). Thus, both peripheral and central lesions appcar to alter the strength of the connections between normally present representations and their target muscles.

\section{Site of change}

Neonatal amputation produces a pattern of MI representation that is clearly different from that found in normal rats. However, electrical stimulation mapping of the cerebral cortex does not necessarily demonstrate that the substrate for altered body representation patterns is within MI. The changed relationship between MI and the proximal forelimb muscles in neonatally injured rats could be mediated by sprouting of distal segments of sectioned axons of distal forelimb motor neurons into proximal forelimb muscles. Since the motor neuron pools of the distal forelimb were largely absent ipsilateral to the amputation, shifts in the targets of denervated alpha motor neurons are unlikely, though a few remaining distal motor neurons could account for a part of the change in MI representation pattern. It is equally unlikely that an expansion of the vibrissa representation occurs from the sprouting of cervical motor neurons into the distant and already innervated vibrissa musculature. By contrast, al- tered connectivity at any one or all of a number of central sites could produce the map changes we observed. For example, there could be a shift in the conncctions of an MI target from onc alpha motor neuron cell group to a neighboring cell group in the spinal cord. This cannot be ruled out since monosynaptic connections from MI to the cervical motor neurons have been identified in rats (Elger et al., 1977). Other possibilities, such as a shift within the cortex or in subcortical relay structures, are equally viable candidates. The presence of an occult vibrissa representation in the presumptive forelimb region might suggest a cortical site of change, since these 2 representations are contiguous in MI but are quite separate in the brain stem and the spinal cord.

\section{Developmental mechanisms for changes in MI representation pattern}

Since MI is relatively immature on the first postnatal day, the changes that were observed in these experiments might reflect disordering of ongoing developmental processes. The final migration of cells to the superficial neocortical layers, ingrowth of thalamic afferent fibers, and the bulk of corticospinal synapse formation (Donatelle, 1977; Wise and Jones, 1977; Killackey and Belford, 1979; Schreyer and Jones, 1982) occur after the postnatal day 1 nerve lesion that was employed here. The adult MI somatotopic representation pattern appears to develop fully only in the third week of life in rats (Cox and Humphrey, 1986). In agreement with previous studies of the effects of nerve injury on the spinal cord (Aldskogius and Risling, 1981; Schmalbruch, 1984), forelimb amputation resulted in a marked reduction in the size of ascending sensory pathways and in the number of motor neurons in the cervical enlargement ipsilateral to the lesion. Thus, the functional organization of MI in our experimental rats is set in the absence of normal forelimb target structures and sensory inputs. This abnormal subcortical organization may lead to the formation of connections that are not normally present (Kalil and Reh, 1982), or may result in the retention of widespread connections that are transiently formed during development (Easter et al., 1985). It has recently been shown that loss of subcortical collateral systems can be influenced by central lesions (O'Leary and Stanfield, 1986). Thus, the development of enlarged MI vibrissa or shoulder representations could bc a conscquence of maintenance of projections that are normally lost or ineffective.

Our anatomical study of the corticospinal projection showed no gross alteration in the pyramidal tract system. However, a reduction in the number of corticospinal neurons (Chimelli and Scaravilli, 1985) or chromatolytic reactions, but not obvious degeneration, in MI pyramidal cells following nerve lesions or limb amputation has been reported (Campbell, 1905). The reason for this apparent discrepancy is not clear, but there are several differences among the studies. Campbell (1905) examined the motor cortex of humans that had limb amputations primarily as adults; none of his cases had the amputation as a newborn. Chimelli and Scarvilli's (1985) transections were carried out at a later age than the amputations done in our experiments (postnatal day 4); they transected a hindlimb nerve, and they made detailed quantitative measurements of cell number and area of the corticospinal tract. The nearly $50 \%$ reduction in corticospinal cells reported in the latter study was not evident in our material. A reduction in the number of cortical projections labeled by spinal cord injection of retrograde anatomical tracers could indicate a loss of cortical neurons or a switch from 
spinal targets to a brain stem target for some cortical neurons. The latter interpretation would be consistent with the development of a larger vibrissa representation in MI. Perhaps a more extensive quantitative analysis of the corticospinal system will reveal these changes in our paradigm.

We do not know what mechanisms lead to the development of novel representation patterns in MI. One possibility is altered sensory input to MI produced by destruction of peripheral afferents. Dawson and Killackey (1987) have shown that digit amputations disrupt enzyme-staining patterns and perhaps thalamic fiber distribution in SI. This observation, coupled with our sensory mapping experiments, indicates that MI would receive abnormal sensory input from SI following amputation. These changes could shape the pattern of representation in MI. Less direct "humoral factors" could influence the strength of developing synapses. For example, Cope et al. (1980) have shown that the strength of spinal Ia afferent inputs to motor ncurons can be altered following lesions made in connectionally isolated segments of the spinal cord. This result suggests that factors produced by nerve damage can influence synaptic strength at remote sites in the absence of direct connections.

\section{Absence of the overlap zone}

The inability to evoke shoulder or trunk movements from the forelimb region of SI suggests that this region fails to develop normally following amputation. However, vibrissa movements could be evoked from this region in some animals, though the reason for this is not clear. Normally, cells in this part of SI respond to cutaneous stimulation of the distal forelimb. This area also contributes directly to motor output, as demonstrated by low intracortical electrical stimulation thresholds. These features suggest that the overlap zone may mediate movements that are initiated or modified by cutaneous information from the distal forelimb. The presence of cutaneous input from the trunk and shoulder might lead to the prediction that movement of these body parts would be evoked by stimulating in the overlap zone. The failure of this region to develop its usual features is not dependent on sensory input because cutaneous input to this cortical zone is preserved by presumed expansion of the SI trunk and shoulder representations towards the agranular cortex. This result might suggest a dynamic interaction between sensory input and the development of some types of motor output.

\section{Functional significance}

The behavioral consequences of alterations in MI organization are not clear. These forms of reorganization in the motor system could contribute to enhanced motor control of intact structures or could disrupt normal functioning. Generally, it has been thought that lesions early in life have a less devastating effect on motor (Kennard, 1942) or sensory (Simons and Finger, 1984; Leonard and Goldberger, 1987) function. However, early lesions may disrupt ongoing developmental processes that are necessary for compensatory responses, thus leading to less recovery after lesions in young animals, as has been shown recently in rat SI cortex (Wall and Cusick, 1986). Our recent evidence, showing that similar forms of change in MI representation pattern occur if nerve lesions are made in adult rats (Sanes et al., 1988), suggests that $\mathrm{MI}$ representation patterns continue to be malleable in fully developed animals. This presumed lifelong ability for restructuring of cortical representation patterns has been made previously for sensory representations (Merzenich and
Kaas, 1982; Kaas et al., 1983). Thereforc, it appcars that a general principle of the modifiability of cerebral cortex, related to sensation or motor output, is emerging. In general, cortical modifiability may depend on the availability of target cells, inputs from other brain regions, and inputs from peripheral end organs. The mechanisms for changes in MI organization are, at best, uncertain, but they could provide strategies for promoting maximal recovery subsequent to lesions of either peripheral or central neural pathways and suggest that the cortical contribution to motor performance may be altered by experience.

\section{References}

Aldskogius, H., and M. Risling (1981) Effect of sciatic neurectomy on neuronal number and size distribution in the L7 ganglion of kittens. Exp. Neurol. 74: 597-604.

Campbell, A. W. (1905) Histological Studies on the Localisation of Cerebral Functions, Cambridge U. P., Cambridge, UK.

Chimelli, L., and F. Scaravilli (1985) Secondary transneuronal degeneration: Cortical changes induced by peripheral nerve section in neonatal rats. Neurosci. Lett. 57: 57-63.

Cope, T. C., S. G. Nelson, and L. M. Mendell (1980) Factors outside the neuraxis mediate the acute increase in EPSP amplitude caudal to spinal cord transection. J. Neurophysiol. 44: 174-183.

Cox, M., and D. R. Humphrey (1986) Development of motor cortex excitability in normal and in neonatally brain injured rats. Soc. Neurosci. Abstr. 12: 1119.

Dawson, D. R., and H. P. Killackey (1987) The organization and mutability of the forepaw and hindpaw representations in the somatosensory cortex of the neonatal rat. J. Comp. Neurol. 256: 246256.

Donatelle, J. M. (1977) Growth of the corticospinal tract and the development of placing reactions in the postnatal rat. J. Comp. Neurol. 175: 207-232.

Donoghue, J. P. (1985) Contrasting properties of neurons in two parts of the primary motor cortex of the awake rat. Brain Res. 333: 173177.

Donoghue, J. P., and J. N. Sanes (1987) Peripheral nerve injury in developing rats reorganizes representation pattern in motor cortex. Proc. Natl. Acad. Sci. USA 84: 1123-1126.

Donoghue, J. P., and S. P. Wise (1982) Rat motor cortex: Cytoarchitecture and microstimulation mapping. J. Comp. Neurol. 212: 7688.

Easter, S. S., Jr., D. Purves, P. Rakic, and N. C. Spitzer (1985) The changing view of neural specificity. Sciencc 230: 507-511.

Elger, C. E., E. J. Speckman, H. Caspers, and R. W. C. Janzen (1977) Corticospinal projections in the rat. I. Monosynaptic and polysynaptic responses of cervical motoneurons to epicortical stimulation. Exp. Brain Res. 28: 385-404.

Evarts, E. V. (1981) Role of motor cortex in voluntary movements in primates. In Handbook of Physiology, Sec. 1: The Nervous System, vol. 2, Motor Control, J. M. Brookhart, V. B. Mountcastle, V. B. Brooks, and S. R. Gieger, eds., pp. 1083-1120, American Physiological Society, Bethesda, MD.

Ezure, K., and T. Oshima (1985) Lateral spread of neuronal activity within the motor cortex investigated with intracellular responses to distant epicortical stimulation. Jpn. J. Physiol. 35: 223-249.

Hall, R. D., and E. P. Lindholm (1974) Organization of motor and somatosensory ncocortex in the albino rat. Brain Res. 66: 23-38.

Harris, R. M., and T. A. Woolsey (1981) Dendritic plasticity in mouse barrel cortex following postnatal vibrissa follicle damage. J. Comp. Neurol. 196: 357-376.

Horne, M., and R. Porter (1971) The effects of prolonged cortical stimulation on the natural activity of neurones in the precentral gyrus of conscious monkeys. Brain Res. 34: 115-126.

Hubel, D. H., and T. N. Wiesel (1965) Binocular interaction in striate cortex of kittens reared with artificial squint. J. Neurophysiol. 28: 1041-1059.

Hubel, D. H., T. N. Wiesel, and S. LeVay (1977) Plasticity of ocular dominance columns in monkey striate cortex. Phil. Trans. R. Soc. Lond. [Biol.] 278: 377-409.

Hummelsheim, H., and M. Wiesendanger (1986) Is the hindlimb rep- 
resentation of the rat's cortex a "sensorimotor amalgam"? Brain Res. 346: 75-81.

Humphrey, D. R., and D. J. Reed (1983) Separate cortical systems for control of joint movement and joint stiffness: Reciprocal activation and coactivation of antagonist muscles. In Motor Control Mechanisms in Health and Disease. J. E. Desmedt, ed., pp. 347-372, Raven, New York.

Jeanmonod, D., F. L. Rice, and H. Van der Loos (1981) Mouse somatosensory cortex alterations in the barrel field following receptor injury at different early postnatal ages. Neuroscience 6: 1503-1535.

Kaas, J. H., M. M. Merzenich, and H. P. Killackey (1983) The reorganization of somatosensory cortex following peripheral nerve damage in adult and developing mammals. Annu. Rev. Neurosci. 6 : 325-356.

Kalaska, J., and B. Pomeranz (1979) Chronic paw deafferentation causes an age-dependent appearance of novel responses from forearm in "paw cortex" of kittens and adult cats. J. Neurophysiol. 42: 618633.

Kalil, K., and T. Reh (1982) A light and electron microscopic study of regrowing pyramidal tract fibers. J. Comp. Neurol. 211: 265-275.

Kartje-Tillotson, G., E. J. Neafsey and A. J. Castro (1985) Electrophysiological analysis of motor cortical plasticity after cortical lesions in newborn rats. Brain Res. 332: 103-111.

Kelehan, A. M., R. H. Ray, L. V. Carson, C. E. Massey, and G. S. Doetsch (1981) Functional reorganization of adult raccoon somatosensory cortex following neonatal digit amputation. Brain Res. 223: $152-159$.

Kennard, M. A. (1942) Cortical reorganization of motor function: Studies on series of monkeys of various ages from infancy to maturity. Arch. Neurol. Psychiatry 47: 227-240.

Killackey, H. P., and G. R. Belford (1979) The formation of afferent patterns in the somatosensory cortex of the neonatal rat. J. Comp. Neurol. 183: 285-304.

Killackey, H. P., G. R. Belford, R. Ryugo, and D. K. Ryugo (1976) Anomalous organization of thalamocortical projections consequent to vibrissae removal in the newborn rat and mouse. Brain Res. 104: 309-315.

Leonard, C. T., and M. E. Goldberger (1987) Consequences of damage to the sensorimotor cortex in neonatal and adult cats. II. Maintenance of exuberant projections. Brain Res. 429: 15-30.

Merzenich, M. M., and J. H. Kaas (1982) Reorganization of mammalian somatosensory cortex following peripheral nerve injury. Trends Neurosci. 5: 434-436.

Mitz, A., and D. R. Humphrey (1986) Intracortical stimulation in pyramidotomized monkeys. Neurosci. Lett. 64: 59-64.

Neafsey, E. J., and C. F. Sievert (1982) A second forelimb area exists in the rat frontal cortex. Brain Res. 232: 151-156.

Neafsey, E. J., E. L. Bold, G. Haas, K. M. Hurley-Gius, G. Quirk, C. F. Sievert, and R. R. Terreberry (1986) The organization of the rat motor cortex: A microstimulation mapping study. Brain Res. 396: $77-96$.

O'Donoghue, D. L., G. Kartje-Tillotson, E. J. Neafsey, and A. J. Castro (1986) A study of forelimb movements evoked by intracortical microstimulation after hemicerebellectomy in ncwborn, young and adult rats. Brain Res. 385: 311-320.

O'Leary, D. D., and B. B. Stanfield (1986) A transient pyramidal tract projection from the visual cortex in the hamster and its removal by selective collateral elimination. Brain Res. 393: 87-99.

Passingham, R. E., V. H. Perry, and P. Wilkinson (1983) The longterm effects of removal of sensorimotor cortex in infant and adult rhesus monkeys. Brain 106: 675-705.

Pidoux, B., R. Verley, E. Farkas, and J. Scherrer (1979) Projections of the common fur of the muzzle upon the cortical area for mystacial vibrissa in rats dewhiskered at birth. Neurosci. Lett. 11: 301-306.

Ryugo, D. K., R. Ryugo, and H. P. Killackey (1975) Changes in pyramidal cell density consequent to vibrissae removal in the newborn rat. Brain Res. 96: 82-87.
Sanderson, K. J., W. I. Welker, and G. M. Shambes (1984) Reevaluation of motor cortex and of sensory motor overlap in cerebral cortex of albino rats. Brain Res. 292: 251-260.

Sanes, J. N., S. Suner, J. F. Lando, and J. P. Donoghue (1988) Rapid reorganization of adult motor cortex somatic representation patterns after motor nerve injury. Proc. Natl. Acad. Sci. USA 85: 2003-2007.

Sapienza, S., B. Talbi, J. Jacquemin, and D. Albe-Fessard (1981) Relationship between input and output of cells in motor and somatosensory cortices of the chronic awake rat: A study using glass micropipettes. Exp. Brain Res. 43: 47-56.

Schmalbruch, H. (1984) Motoneuron death after sciatic nerve section in newborn rats. J. Comp. Neurol. 224: 252-258.

Schreyer, D. J., and E. G. Jones (1982) Growth and target finding by axons of the corticospinal tract in prenatal and postnatal rats. Neuroscience $7:$ : $1837-1853$.

Sherman, S. M., and P. D. Spear (1982) Organization of visual pathways in normal and visually deprived cats. Physiol. Rev. 62: 738855.

Simons, D. J., and S. Finger (1984) Some factors affecting behavior after brain damage early in life. In Early Brain Damage, vol. 2, S. Finger and C. R. Almli, eds., pp. 327-347, Academic, New York.

Simons, D. J., D. Durham, and T. A. Woolsey (1984) Functional organization of mouse and rat SmI barrel cortex following vibrissal damage on different postnatal days. Somatosensory Res. 1: 207-245.

Steffen, H., and H. Van der Loos (1980) Early lesion of mouse vibrissal follicles: Their influcnces on dendrite orientation in the cortical barrel field. Exp. Brain Res. 40: 419-431.

Stoney, S. D., Jr., W. D. Thompson, and H. Asanuma (1968) Excitation of pyramidal tract cells by intracortical microstimulation: Effective extent of stimulating current. J. Neurophysiol. 31: 659-669.

Van der Loos, H., and T. A. Woolsey (1973) Somatosensory cortex: Structural alterations following early injury to sense organs. Science 179: 395-398.

Waite, P. M. E. (1984) Rearrangement of neuronal responses in the trigeminal system of the rat following peripheral nerve section. $J$. Physiol. (Lond.) 352: 425-445.

Waite, P. M. E., and P. K. Taylor (1978) Removal of whiskers in young rats causes functional changes in cerebral cortex. Nature 274: $600-604$

Wall, J. T., and C. G. Cusick (1986) The representation of peripheral nerve inputs in the S-I hindpaw cortex of rats raised with incompletely innervated hindpaws. J. Neurosci. 6: 1129-1147.

Welker, W., K. J. Sanderson, and G. M. Shambes (1984) Patterns of afferent projections to transitional zones in the somatic sensorimotor cerebral cortex of albino rats. Brain Res. 292: 261-267.

Weller, W. L., and J. I. Johnson (1975) Barrels in cerebral cortex altered by disruption in newborn but not five-day-old mice (Cricetidae and Muridae). Brain Res. 83: 504-508.

Whishaw, I. Q., W. T. O'Connor, and S. B. Dunnett (1986) The contributions of motor cortex, nigrostriatal dopamine and caudateputamen to skilled forelimb use in the rat. Brain 109: 805-843.

Wise, S. P., and J. P. Donoghue (1986) The motor cortex of rodents. In The Cerebral Cortex, vol. 5: Sensory-Motor Areas and Aspects of Cortical Connectivity, E. G. Jones and A. Peters, eds., pp. 243-270, Plenum, New York.

Wise, S. P., and E. G. Jones (1977) Developmental studies of thalamocortical and commissural connections in the rat somatic sensory cortex. J. Comp. Neurol. 178: 187-208.

Woolsey, T. A., and J. R. Wann (1976) Areal changes in mouse cortical barrels following vibrissal damage at different postnatal ages. J. Comp. Neurol. 170: 53-66.

Woolsey, C. N., T. Górska, A. Wetzel, T. C. Erickson, F. J. Earls, and J. M. Allman (1972) Complete unilateral section of the pyramidal tract at the medullary level in Macaca mulatta. Brain Res. 40: 119123. 